\title{
Geoarchaeology: Human adaptation to landscape changes, landscape resilience to human impact and integrating palaeoenvironmental and archaeological records editorial
}

Sjoerd J. Kluiving ${ }^{1,2 *}$

Julie A. Durcan ${ }^{3}$

Wiebke Bebermeier ${ }^{4}$

Robyn Inglis ${ }^{5,6}$

Vanessa M.A. Heyvaert ${ }^{7,8}$

Andy Howard ${ }^{9}$

Lisa-Marie Shillito ${ }^{10}$

1. Faculty of Humanities, Department of Archaeology, Vrije Universiteit Amsterdam, 1018HV, The Netherlands

2. Research institute for the heritage and history of the Cultural Landscape and Urban Environment (CLUE+), 1018HV, The Netherlands

3. School of Geography and the Environment, University of Oxford, OX1 3J, United Kingdom

4. Institute of Geographical Sciences, Department of Earth Sciences, Freie Universität Berlin, 12249

Germany

5. Department of Archaeology, University of York, YO1 7EP, United Kingdom

6. Department of Environmental Sciences, Macquarie University, Australia

7. Geological Survey of Belgium, 1000 Brussels, Belgium.

8. Department of Geology, Ghent University, 9000 Ghent, Belgium.

9. Landscape Research \& Management, Bridgnorth, WV15 5JG, United Kingdom,

10. School of History, Classics and Archaeology, Newcastle University, NE1 7RU, United Kingdom

*Contact author: s.j.kluiving@vu.nl

This special issue covers the EGU 2016 session GM6.2/SSS3.10 'Geoarchaeology: Human adaptation to landscape changes, landscape resilience to human impact and integrating palaeoenvironmental and archaeological records'. This session in Vienna received a high number of abstracts with 32 submitted, comprising 11 oral and 21 poster presentations. This session was supported by the IAG - International Working Group on Geoarchaeology. Currently human-climate-environment interactions are a key research theme within Quaternary Science, Geomorphology and Environmental Archaeology communities (Bebermeier et al, 2012, 2013; Diskin et al, 2013, Engel \& Bruckner, 2014; Kluiving \& Guttmann-Bond, 2012, Kluiving et al, 2012, 2015, 2017; Knittter et al 2015; Verstraeten, 2013, Wilson, 2011).

The aim of this session was highlight geoarchaeological best practice when considering the question of how to analyse and deal with uncertainties in data. This session welcomed papers from individuals or groups that use geoarchaeological approaches to explore past landscape evolution, geomorphological processes, human impact and system response, as well as issues of landscape resilience and human adaptation. This session invited papers which discuss methodological and theoretical approaches to integrating palaeoenvironmental and archaeological records, or which present case studies of this multi-disciplinary approach in action. Themes may include the impacts of environmental change on human development, and also how humans have influenced the environment. Approaches which effectively link multi-scalar datasets were encouraged.

From this session nine thought-provoking and diverse papers are presented here, from individuals and groups that use a variety of geoarchaeological approaches and techniques to consider past landscape evolution, geomorphological processes and system response to natural and anthropogenic drivers. The papers in this volume are ordered geographically from east to west: India (Durcan et al, this issue), 
Jordan (Meister et al, this issue), Egypt (Hamden et al, this issue), Turkey, (Stock et al, this issue), Italy, (Aucelli et al, this issue), The Netherlands (Pierik \& van Lanen, van Lanen \& Pierik), France (Contreras et al, this issue) and Gibraltar (Doerschner et al, this issue).

The paper by Durcan et al. (this issue) explores the relationship between climate, environment and society in northwest India. Using luminescence dating, the study provides new chronological evidence for Holocene fluvial and aeolian activity in the Ghaggar-Hakra interfluve region on the northern margin of the Thar Desert. These luminescence ages are compared to other regional investigations to provide a picture of environmental and cultural change within the Indus basin. The study suggests that there is no clear link to a $4.2 \mathrm{ka}$ abrupt climate event, nor is there a simple switch between the dominance of fluvial and aeolian sedimentation. Instead the ages suggest a highly dynamic geomorphic system during the Holocene. The decline of urbanism within the Indus civilisation was not spatially or temporally instantaneous, and Durcan et al suggest that the same can be said of the geomorphic response of the northern Thar region to climate change. The evidence provided by this paper adds to the emerging picture of the Ghaggar-Hakra interfluve region as a low energy fluvial system during the Holocene, broadly driven by regional changes in the monsoon, though this response appears to be neither simple nor linear.

Meister et al. (this issue) investigate the absolute and relative spatial location of known enclosure sites in the north-eastern Jordanian harra, and examine their first- and second-order characteristics; their approach uses distance and density-based analyses of point patterns, which include geomorphometric and geomorphological site characteristics. The results of these spatial analyses are combined with available archaeological data and a review of traditional herding practices, and represents the first attempt to investigate the spatial distribution of clustered enclosures throughout this region. Analysis of more than 9000 clustered enclosures suggests that a relatively large number of people resided in this area on a temporary basis. Migration patterns during the recent past might have been similar throughout discreet historical periods and perhaps into later prehistory. This research concludes that clustered enclosures should be examined in greater depth by archaeological excavation and survey in order to gain an enhanced understanding of the function of the individual structures and their chronology. Such knowledge is required and essential to understand the nature of past pastoral societies in north-east Jordan.

The paper of Hamden et al. (this issue) focuses on the floodplain sediments of the Nile in the Memphite region of Egypt and their implications for elucidating the: (1) temporal changes in sediment source; (2) variations in the palaeoclimatic and palaeoenvironmental conditions during the Middle and Late Holocene; (3) impact of changing flood frequency and magnitude on the landscape. The Holocene sequence of the floodplain sediments around Saqqara-Memphis was subdivided into six sedimentary units (II-VII), each characterized by its own sedimentological, mineralogical and geochemical signature, as well as characteristic archaeological remains. Analysis of the sediments demonstrated that throughout archaeological history the dominant source waters of the Nile switched regularly between the 'Blue' and 'White' headwaters. Low Nile flow episodes were recorded at 5.2, 4.2, 3.5 and $2.7 \mathrm{kyr}$ cal BP. The second event corresponds to the First Intermediate Period (FIP) and the third likely coincides with the Second Intermediate Period (2nd IP), which are both periods of disorder in Egypt.

Stock et al. (this issue) carried out a detailed geophysical and geoarchaeological investigation around a hill of mica schist in the western Küçük Menderes graben, west of Ephesus, Turkey. A range of methodological approaches including the analysis of geomagnetic and georadar data and sediments collected using a vibrocore were used to investigate this landform which was of high importance during the Byzantine period. The study revealed that during the 2nd millennium BCE, the hill became an island as a result of marine transgression. However, around CE 400 it became reconnected to the 
mainland, forming a peninsula, which became an attractive setting, and led to the construction of a hilltop church to control access to the holy sites of Ephesus. Massive, dense stone layers were deposited around the hill during the 4th/5th centuries CE and were most likely associated with the construction works mentioned previously. In addition, a shallow harbour was created to the northeast of the hill for use by small ships. The harbour was connected to the sea via the Küçük Menderes river, even though the edge of the coastline had, by this time, already shifted further to the west.

Aucelli et al. (this issue) conducted a geoarchaeological study of the Posillipo promontory near Naples, Italy, in order to constrain vertical movements suffered by the eastern periphery of the Campi Flegrei area over the last 2000 years. Three coastal geoarchaeological sites (Nisida Roman port, Marechiaro Roman port and the remains off Villa Rosebery) were studied by means of terrestrial geomorphological observations and marine geophysical survey (Side Scan Sonar and Single Beam echo sounder). The research has led to the identification of two relative palaeo-sea levels: one assigned to the 1 st century $B C$ at $-4.4 /-5$ meters $\pm 0.5 \mathrm{~m}$ and another attributable to the $1^{\text {st }}$ century $A D$ at -3 meters $\pm 0.5 \mathrm{~m}$. While there is less than 2 decimetres difference between the two palaeo-sea levels, the changes are attributed to eustasy (Lambeck et al., 2011). Other changes ( 2 meters $\pm 0.5 \mathrm{~m}$ ) can be ascribed to a phase of accelerated subsidence, which has yet to be precisely dated and whose duration could have been as short as a few years or decades. In terms of human adaptation, the archaeological evidence suggests that Palazzo degli Spiriti was restored and the rooms inundated by the sea closed; in contrast, the breakwater of Marechiaro and the villa foundations at Rosebery were probably raised in response to the relative sea level rise.

In order to better understand the interaction between landscape and settlement dynamics in the Netherlands, Pierik and van Lanen (this issue) postulated that elevation determined the sensitivity of settlement to changes in flood regime. Their aim was therefore to acquire a more detailed understanding of settlement between the higher and lower parts of alluvial ridges in the Rhine-Meuse delta in the Netherlands. Although cultural factors must also have played a role in the observed geographical and altitudinal shifts in the location of settlement, these can only can be fully explained by including landscape dynamics in the analysis of observed patterns. They conclude that: 1) during the first millennium CE habitation occurred mainly on the higher parts of the alluvial ridges, with $40 \%$ of the settlements being situated on ridges without an underlying channel belt; 2 ) between 270-750 $\mathrm{CE}$, settlements shifted towards higher locations, at first in relatively low-lying parts of the delta, later in somewhat higher parts of the central delta; 3 ) between 270-750 CE, settlements close to newlyformed large river channels were either relocated to higher ground or abandoned.

Van Lanen \& Pierik (this issue) contributed a second paper on the Rhine-Meuse delta, to model Roman and early-medieval route networks in the landscape as an expression of environmental and cultural change. The network-friction method (NFM) can be applied on a regional scale in order to obtain highresolution results and is able to model route networks and network stability in the past. The approach is based on their earlier published NFM, which is further developed and tested in this paper. Maps and route networks were calculated for three time slices: $100 \mathrm{CE}, 500 \mathrm{CE}$ and $900 \mathrm{CE}$. This shows that large parts of the Rhine-Meuse delta were used continuously during the Roman period and Early Middle Ages, despite dynamic landscape evolution that impacts upon local settlement and habitation. Validation of the models' outputs showed that the NFM is able to calculate the link between route networks, settlement patterns and the physical landscape. The current approach appears to be best suited for supra-regional analyses and would benefit from integration with other route-network modelling techniques in order to also allow regional or micro-regional reconstructions.

The paper of Contreras et al. (this issue) explores the relationship between past climate and prehistoric Mediterranean agriculture by adapting a process-based dynamic vegetation model to estimate potential agricultural productivity (PAGp) under climate scenarios that characterize the 
extremes of Mediterranean climate in the Holocene. The model was calibrated for past crops and agricultural practices and used a downscaling approach to produce high spatio-temporal resolution palaeoclimate data. The authors produce quantitative estimates of potential yields under past climatic conditions derived from four Holocene climatic extremes (warm/wet, warm/dry, cold/wet, and cold/dry) under two different assumptions about the intensity of agricultural practice (approximate high and low limits). The authors demonstrate their methodology with reference to a case study from Provence (south-west France), modelling past agriculture and considering the implications of the range of variability in PAGp under distinct climate conditions. The results of this work provide an understanding of the envelopes of possibility within which past inhabitants of the region would have practiced agriculture, as well as how these envelopes expanded and contracted over time due to both climate forcing and human activity.

Doerschner et al. (this issue) applied quartz optically stimulated luminescence (OSL) dating from the uppermost $\sim 4 \mathrm{~m}$ of the Late Pleistocene geoarchaeological deposits at Vanguard Cave, Gibraltar. The authors use single-grain and multi-grain dating techniques to clarify the depositional history of the sedimentary sequence, as well as to assess the reliability of the two dating approaches and their potential for future chronological studies at the site. The single-grain and multi-grain ages are consistent with one another and indicate no partial bleaching or post-depositional mixing of the sediments. Results suggest that Vanguard Cave experienced continuous sediment accumulation probably since the last sea-level highstand in MIS 5 , and was completely infilled by $\sim 43$ ka (MIS3). The eastern side of the Rock of Gibraltar faced an exposed coastal shelf covered with savannah and an active coastal dune system during MIS 3 . Their results indicate that similar environmental conditions are likely to have persisted also during MIS 4 and large parts of MIS 5. OSL dating from these periods using multi-grain aliquots larger than $1 \mathrm{~mm}$ were found to produce dates that significantly overestimated the true burial age of the sediments. Therefore, small multi-grain aliquots, or preferably dating of individual grains is recommended to reliably date the lower part of stratigraphical sequences in similar depositional settings.

The majority of natural scientists now believe that proxy environmental data is demonstrating significant anthropogenic changes to contemporary global climates, which in turn, affects landscape system thresholds and alters spatial patterns, intensity and magnitude of geomorphological processes. Geoarchaeology can approach these questions of human causality, environmental resilience and sustainability from a medium to long-term perspective. This has the critical advantage that it can, implicitly or explicitly, include consideration of the feedback associated with these changes on human socio-cultural systems.

At EGU 2017 it was debated that geoarchaeology shouldn't be called a new discipline, but rather a forum where both contrasting research domains, i.e. geography, geology and archaeology can learn from one another, not only from research questions formulated jointly, but also by integrating and evaluating disparate datasets and publishing the results as seamless narratives (cf. Verstraeten, 2013). This current issue, reflecting the largest Geoarchaeology session ever held at an EGU conference, proves the mature, interdisciplinary status of geoarchaeology, maintaining scientific rigour as well as providing examples of valuable collaboration. More than forty years ago Colin Renfrew stated that every problem in archaeology starts as a geoarchaeological problem (Renfrew, 1976), and this set of papers demonstrate how ever increasing interaction between archaeology and geosciences could facilitate insightful research, both now and in the future. 
Aucelli, P., Cinque, A., Mattei, G., Pappone, G., Rizzo, A., 2019. Studying relative sea level change and correlative adaptation of coastal structures on submerged Roman time ruins nearby Naples (southern Italy), Quaternary International,

Bebermeier, W., Hoelzmann, P., Kaiser, E., \& Krause, J. 2013 LAC 2012: 2nd International Landscape and Archaeology Conference, Berlin; Quaternary International, 312, 1-140.

Bebermeier, W., Hebenstreit, R., Kaiser, E., \& Krause, J. 2012. Landscape Archaeology Conference (LAC 2012); eTopoi. Journal for Ancient Studies, Special Volume 3, 1-410.

Burgers, G. L. M., Kluiving, S. J., \& Hermans, R. A. E. (2016) Multi-, Inter- and Transdisciplinary Research in Landscape Archaeology: Proceedings of the 3rd International Landscape Archaeology Conference in Rome, Italy. University Library, Vrije Universiteit Amsterdam.

Butzer, K.W., 2008. Challenges for a cross-disciplinary geoarchaeology: the intersection between environmental history and geomorphology. Geomorphology 101, 402-411.

Contreras, D. A., Bondeau, A., Guiot, J., Kirman, A., Hiriart, E., Bernard, L., Suarez, R., Fader, M., 2019. From paleoclimate variables to prehistoric agriculture: Using a process-based agro-ecosystem model to simulate the impacts of Holocene climate change on potential agricultural productivity in Provence, France, Quaternary International,

Diskin, S., Heyvaert, V., Pavlopoulos, K., Schütt, B., 2013. Geoarchaeology: a toolbox of approaches applied in a multidisciplinary research discipline. Quaternary International, 308-309, 1-282.

Doerschner, N., Fitzsimmons, K.E., Blasco, R., Finlayson, G., Rodríguez-Vidal, J., Rosell, J., Hublin, J-J., Finlayson, C., 2019. Chronology of the Late Pleistocene archaeological sequence at Vanguard Cave, Gibraltar: Insights from quartz single and multiple grain luminescence dating, Quaternary International,

Durcan, J.A., Thomas, D. S.G. Gupta, S., Pawar, V., Singh, R.N., Petrie, C.A., 2019. Holocene landscape dynamics in the Ghaggar-Hakra palaeochannel region at the northern edge of the Thar Desert, northwest India, Quaternary International,

Engel, M., Brückner, H., 2014. Late Quaternary environments and societies: progress in geoarchaeology. Zeitschrift für Geomorphologie, Supplementbände 58, 1-6.

M.A. Hamdan, F.A. Hassan, R.J. Flower, S.A.G. Leroy, N.A. Shallaly, A. Flynn,

Source of Nile sediments in the floodplain at Saqqara inferred from mineralogical, geochemical, and pollen data, and their palaeoclimatic and geoarchaeological significance,

Quaternary International,

Kluiving, S. J., \& Guttmann-Bond, E. 2012; Landscape Archaeology between Art and Science: From a Multi- to an Interdisciplinary Approach; Amsterdam University Press, $560 \mathrm{p}$.

Kluiving, S., Lehmkuhl, F., \& Schütt, B. 2012. LAC 2010: 1st international conference on Landscape Archaeology; Quaternary International, 251, 1-142.

Kluiving, S.J., Engel, M., Heyvaert, V.M., Howard, A.J., 2015. Where earth scientists meet Cleopatra: Geoarchaeology and geoprospection of ancient landscapes. Quaternary International, 367, 1-3. 
Kluiving, S. J., Kootker, L. M., \& Hermans, R. A. E. (2017). Interdisciplinarity between science and humanities. Sidestone Press, $184 \mathrm{p}$.

Knitter, D. Bebermeier, W., \& Nakoinz, O. 2015. Bridging the Gap - Integrated Approaches in Landscape Archaeology; eTopoi. Journal for Ancient Studies, Special Volume 4, 1-206.

Lambeck, K., Antonioli, F., Anzidei, M., Ferranti, L., Leoni, G., Scicchitano, G., Silenzi, S., 2011. Sea level change along the Italian coasts during Holocene and prediction for the future. Quaternary International, 232, 250-257.

Meister, J., Knitter, D., Krause, J. Müller-Neuhof, B., Schütt, B., 2019. A pastoral landscape for millennia: Investigating pastoral mobility in northeastern Jordan using quantitative spatial analyses, Quaternary International,

Pierik, H. J., Van Lanen, R.J., 2019. Roman and early-medieval habitation patterns in a delta landscape: The link between settlement elevation and landscape dynamics, Quaternary International,

Renfrew, C. (1976) Archaeology and the earth sciences. In: D.A. Davidson and M.I. Shackley (eds) Geoarchaeology: Earth Science and the Past, Duckworth, London, 1-5.

Stock, F., Halder, S., Opitz, S., Pint, A., Seren, S., Ladstätter, S. Brückner, H., 2019. Late Holocene coastline and landscape changes to the west of Ephesus, Turkey, Quaternary International,

Van Lanen, R.J., Pierik, H.J., 2019. Calculating connectivity patterns in delta landscapes: Modelling Roman and early-medieval route networks and their stability in dynamic lowlands, Quaternary International,

Verstraeten G. 2013. The Relation between Archaeology and Geography in Studying Past Humanenvironment Interactions: Is Interdisciplinary Geoarchaeology the Answer? In Poblome, J. (Ed.). (2013). Exempli Gratia: Sagalassos, Marc Waelkens and Interdisciplinary Archaeology. Leuven University Press, 71-80.

Wilson, C. (ed.) 2011. The role of geoarchaeology in extending our perspective. Geological Society, London, Special Publications, 352, 1-9. 